\title{
Circulating Tumor Cell Detection in Lung Cancer Animal Model
}

\author{
Yooyoung Chong, M.D., Yong Chae Jung, M.D., Euidoo Hwang, M.D., Hyun Jin Cho, M.D., Ph.D., \\ Min-Woong Kang, M.D., Ph.D., Myung Hoon Na, M.D., Ph.D. \\ Department of Thoracic and Cardiovascular Surgery, Chungnam National University Hospital, Chungnam National University School of Medicine, Daejeon, Korea
}

\author{
ARTICLE INFO \\ Received May 12, 2021 \\ Revised July 20, 2021 \\ Accepted August 5, 2021 \\ Corresponding author \\ Myung Hoon $\mathrm{Na}$ \\ Tel $82-42-280-7375$ \\ Fax 82-42-280-7373 \\ E-mail thomasna@cnu.ac.kr \\ ORCID \\ https://orcid.org/0000-0002-7458-1798
}

\begin{abstract}
Background: Metastasis and recurrence of primary cancer are the main causes of cancer mortality. Disseminated tumor cells refer to cancer cells that cause metastasis from primary cancer to other organs. Several recent studies have suggested that circulating tumor cells (CTCS) are associated with the clinical stage, cancer recurrence, cancer metastasis, and prognosis. There are several methods of isolating CTCs from whole blood; in particular, using a membrane filtration system is advantageous due to its cost-effectiveness and availability in clinical settings. In this study, an animal model of lung cancer was established in nude mice using the human large cell lung cancer cell line $\mathrm{H} 460$.

Methods: Six-week-old nude mice were used. The H460 lung cancer cell line was injected subcutaneously into the nude mice. Blood samples were obtained from the orbital area before cell line injection, 2 weeks after injection, and 2 weeks after tumor excision. Blood samples were filtered using a polycarbonate 12-well Transwell membrane (Corning Inc., Corning, NY, USA). An indirect immunofluorescence assay was performed with the epithelial cell adhesion molecule antibody. The number of stained cells was counted using fluorescence microscopy.

Results: The average size of the tumor masses was $35.83 \mathrm{~mm}$. The stained cells were counted before inoculation, 2 weeks after inoculation, and 2 weeks after tumor excision. Cancer cells generally increased after inoculation and decreased after tumor resection. Conclusion: The CTC detection method using the commercial polycarbonate 12-well Transwell (Corning Inc.) membrane is advantageous in terms of cost-effectiveness and convenience.
\end{abstract}

Keywords: Animal model, Lung neoplasms, Malignant tumor

\section{Introduction}

Cancer is the leading cause of death in most industrialized counties. Metastasis and recurrence of primary cancer are the main causes of cancer mortality [1]. Disseminated tumor cells refer to cancer cells that cause metastasis from primary cancer to other organs [2]. Among these cancer cells, those that penetrate the blood vessel wall and float in the blood circulation are known as circulating tumor cells (CTCs). Several recent studies have suggested that CTCs are associated with the clinical stage, cancer recurrence, cancer metastasis, and prognosis [3-6]. When the number of CTCs in blood samples from breast cancer patients was 5 or more, the recurrence rate was higher and the survival rate was lower than in patients with a lower CTC count [7].
There are several methods of isolating CTCs from whole blood. The oldest method is the density gradient centrifugation method, wherein CTCs are isolated with immunohistochemical staining of the epithelial marker cytokeratin from cells separated by centrifuging whole blood [8]. However, this method has the disadvantages of being time-consuming and costly, as well as having a reproducibility of less than $70 \%$.

Another method is to use magnetic beads. Magnetic bead technology separates CTCs from whole blood through the magnetic force exerted by magnetic beads attached to antibodies. However, as there is considerable variability in the quantity of proteins expressed in the cell membrane of each cancer cell, the yield ratio varies significantly, from $9 \%$ to $90 \%$ [8-11]. Moreover, expensive equip- 
ment is required to detect the separated CTCs.

Another method of CTC separation is based on the different sizes of cells in the blood. This technique, known as the membrane filtration system (MEMS) method, takes advantage of the fact that CTCs are larger than red blood cells or platelets $[12,13]$. The MEMS method using a microfabricated filter has the advantages of being cheaper than other methods; furthermore, it is possible to freely change the size and location of the pores, and the equipment is easily available in clinical settings as it only requires immunostaining after filtering the collected blood with the MEMS, which does not take a long time. In a recent CTC detection study using MEMS, an $8-\mu \mathrm{m}$ pore was used to isolate CTCs, and $90 \%$ of CTCs were detected within a short time [14].

In this study, an animal model of lung cancer was established by subcutaneous tissue injection in nude mice using the human large cell lung cancer cell line H460. CTCs were then detected in the blood of these mice using a commercially available filtering system with a pore size of $8 \mu \mathrm{m}$. The purpose of this experiment was to determine the applicability of this tool for the filtration and detection of CTCs.

\section{Methods}

To establish the animal model, 6 -week-old nude mice weighing $25 \mathrm{~g}$ were used. Briefly, $1 \times 10^{6}$ cells were injected into the subcutaneous tissue in the posterolateral regions of the chest and abdomen of nude mice.

After injection of the lung cancer cell line, $1 \mathrm{~mL}$ of blood was collected from the periorbital area into an ethylenediaminetetraacetic acid (EDTA) tube containing $1 \mathrm{~mL}$ of normal saline. Two weeks after the injection of the lung cancer cell line, $1 \mathrm{mg}$ of ketamine and $0.1 \mathrm{mg}$ of xylazine were injected intraperitoneally for anesthesia. Then, $1 \mathrm{~mL}$ of blood was collected from the area around the eye in the same manner mentioned above. After blood collection, the mass was resected along with the surrounding subcutaneous tissue; the area was then sutured. Two weeks after resection of the tumor mass, $1 \mathrm{~mL}$ of blood was collected from the area around the eye in the same manner.

To detect CTCs, a commercially available MEMS system was used. All blood samples were immediately transferred to a 12-well Transwell membrane (Corning Inc., Corning, NY, USA) after collection into EDTA tubes for filtering for 10 minutes (Fig. 1). After filtration, an indirect immunofluorescence assay was performed.

The indirect immunofluorescence method was performed following the instructions for the reagent. A commercially available slide (IT-APF; ImmunoThink Co., Seoul, Korea) was used. The serum was diluted to 1:20. To each well of the slide, $30 \mu \mathrm{L}$ of diluted serum was aliquoted, reacted at $37^{\circ} \mathrm{C}$ for 60 minutes, and washed for $10 \mathrm{~min}$ utes in phosphate-buffered saline. A secondary antibody (fluorescein isothiocyanate-conjugated rabbit anti-human gamma-globulin) was aliquoted, reacted at $37^{\circ} \mathrm{C}$ for 30 minutes, and washed again. The slide was then observed using fluorescence microscopy.

This experiment was finished before the Chungnam National University Hospital Pre-Clinical Research Center was established (August 2013). However, the research followed the Guidelines for Ethical Conduct in the Care and Use of Animals [15-17].

\section{Results}

The animal model of lung cancer was established by the injection of $\mathrm{H} 460$ cells into the subcutaneous tissue of nude mice. $\mathrm{H} 460$ cells $\left(1 \times 10^{6}\right)$ were injected into the pos-
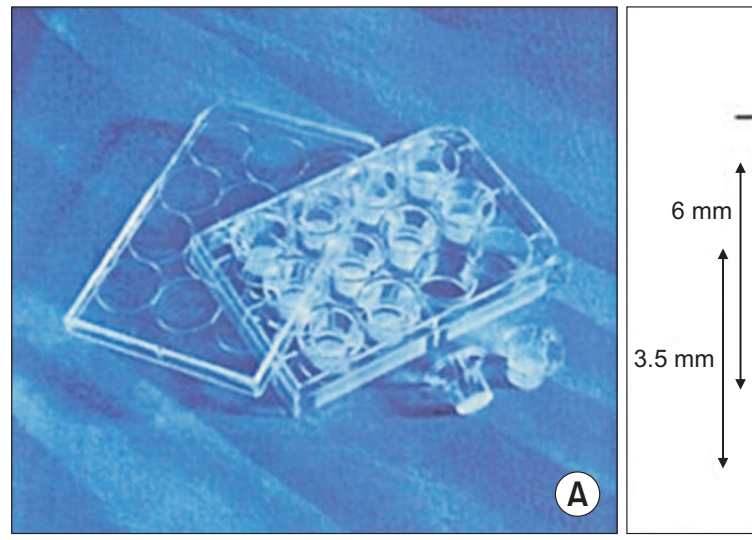

Fig. 1. (A, B) Schematic diagram of the method used to capture circulating tumor cells with a Transwell membrane (Corning Inc., Corning, NY, USA). 
terolateral subcutaneous tissues of the abdomen, considering the weight of nude mice. Although it was confirmed that cancerous tumors grew under the skin 2 weeks after inoculation in the nude mice, the size of the tumor was slightly different for each individual. The sizes of the masses were $30,39,40,39,42$, and $25 \mathrm{~mm}$ for nude mice no. 1 , $2,3,4,5$, and 6 , respectively, with an average size of 35.83 $\mathrm{mm}$ (Fig. 2). Mass resection was performed immediately after the second blood collection. There were no cases of mass recurrence in the 2 -week period after mass resection.

Blood collection was performed 3 times. All samples were obtained by orbital blood collection, and blood was collected before the $\mathrm{H} 460$ inoculation, 2 weeks after inoculation, and 2 weeks after mass removal. After collecting 1 $\mathrm{mL}$ of blood, it was mixed with $1 \mathrm{~mL}$ of physiological saline and stored in an EDTA tube. Blood was collected from the 6 mice successfully without any complications.

Membrane filtering was performed within 5 minutes after blood collection. After transferring the blood samples to a 12-well Transwell (Corning Inc.) membrane and filtering for 10 minutes, it was confirmed that all blood samples came down to the lower cover of the Transwell (Corning Inc.) membrane, and no blood clots occurred in any of the 6 samples during the experiment. After confirming that filtration was complete, the upper cover with the cell filter was separated, and only the lower floor plate was removed; then, the indirect immunofluorescence assay was performed. After membrane filtration, CTCs were confirmed through indirect immunofluorescence with epithelial cell adhesion molecule (EpCAM) and CD45.

In nude mouse no. 1, 45 cells were stained with fluorescence before inoculation with H460. After 2 weeks, 134 cells were stained in the blood before mass resection, and 150 cells were stained 2 weeks after resection. Nude mouse no. 2 had 55 stained cells before inoculation, 16 stained cells before mass resection, and no stained cells 2 weeks after mass resection. Nude mouse no. 3 had 15 stained cells before inoculation, 163 stained cells before mass resection, and 35 stained cells 2 weeks after mass resection. Nude mouse no. 4 had no stained cells before inoculation, 27 stained cells before mass resection, and 13 stained cells 2 weeks after mass resection. Nude mouse no. 5 had 5 stained cells before inoculation, 182 stained cells before mass resection, and 3 stained cells 2 weeks after mass resection. Nude mouse no. 6 had no stained cells before inoculation, 2 stained cells before mass resection, and 3 stained cells 2 weeks after mass resection (Fig. 3).

An increase in CTC levels after inoculation was confirmed in 5 out of the 6 nude mice (80\%). The number of cancer cells tended to decrease after tumor resection. It was not possible to confirm the recurrence of tumors after resection.

\section{Discussion}

CTC detection was performed using a membrane filtra-
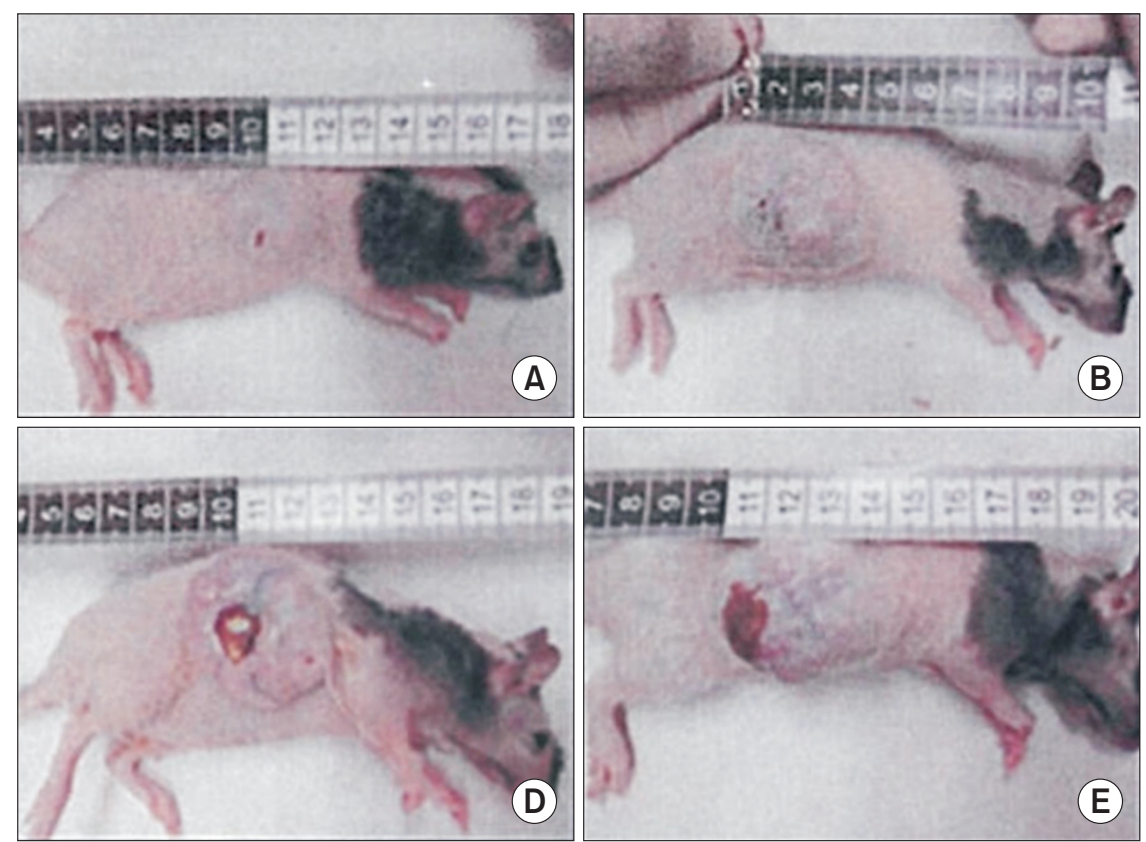

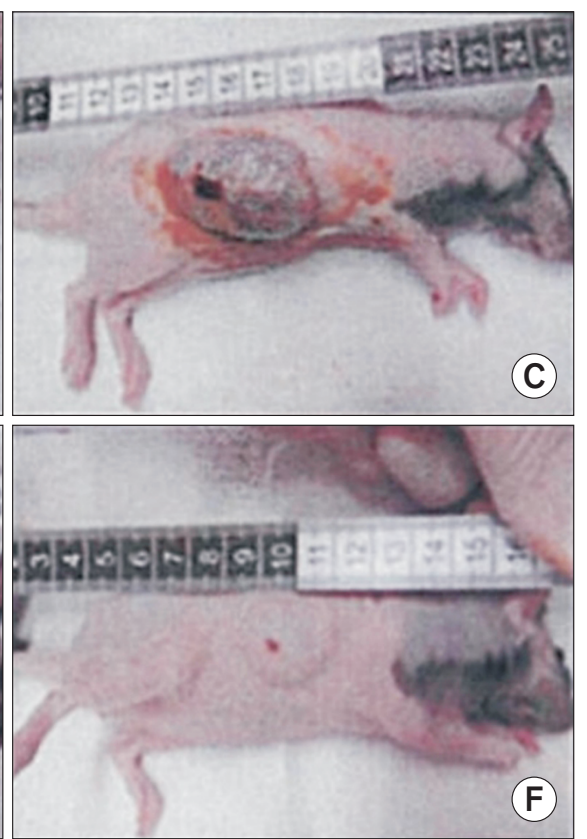

Fig. 2. (A-F) Mass formation: 2 weeks after $\mathrm{H} 460$ cell inoculation. 
Basal
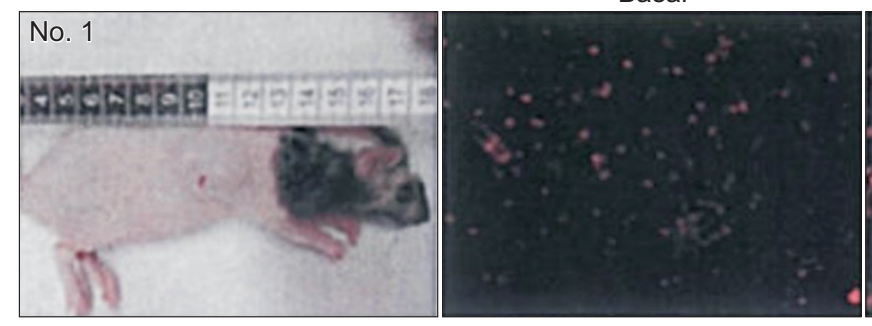

Tumor resection
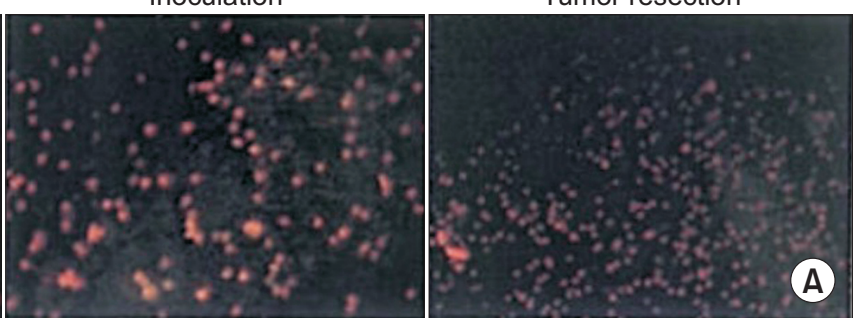
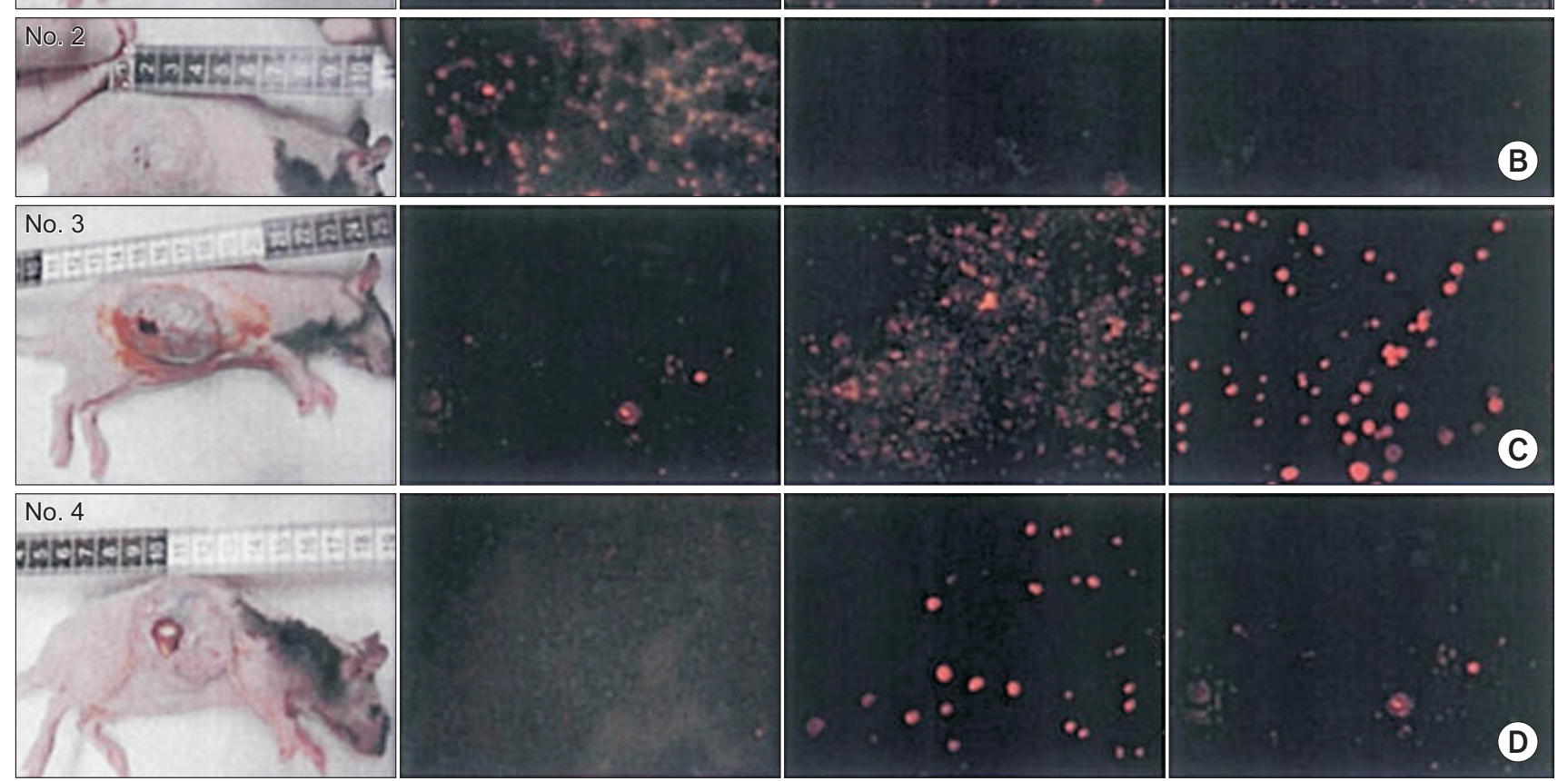

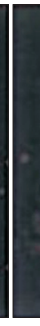

$c$

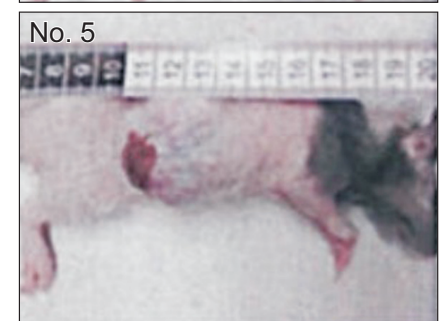

\section{(1)}
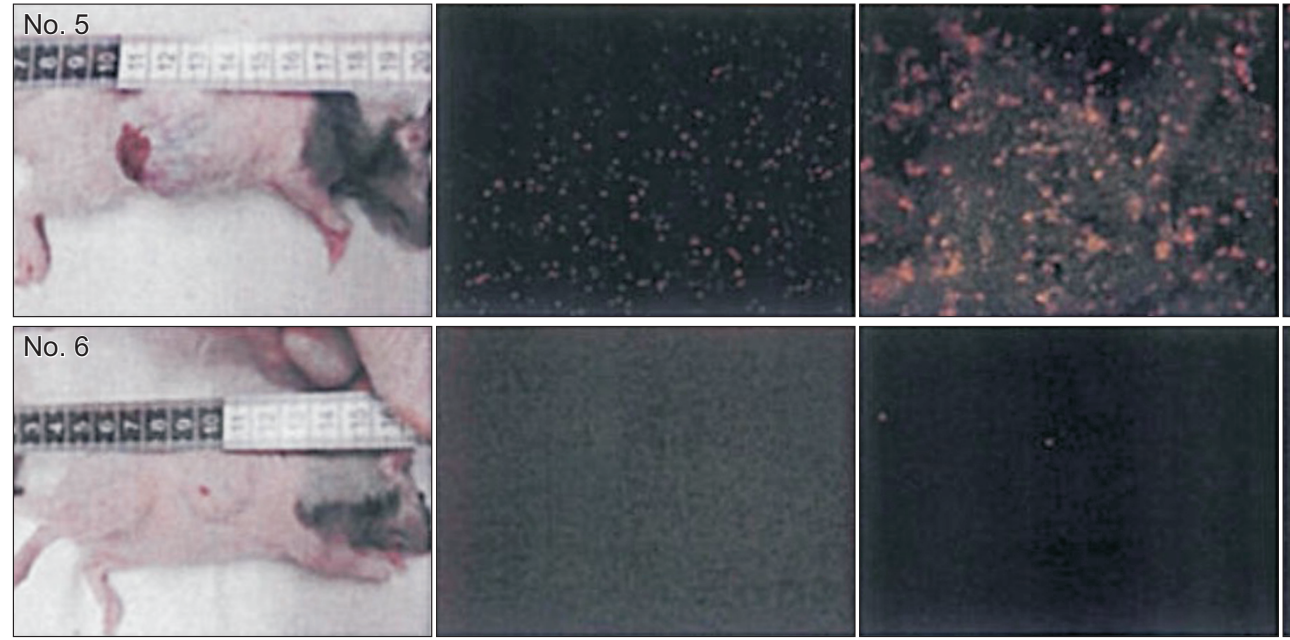

(D)

Fig. 3. (A-F) Results of indirect immunofluorescence.

tion system in the blood of a mouse model of lung cancer. The membrane filtration system is a detection method that takes advantage of the fact that tumor cells of epithelial origin are larger than other cells in the blood. In a previous study using a membrane filtration system with a pore size of $8 \mu \mathrm{m}, 90 \%$ of CTCs were detected when cancer cells were mixed into human blood. As well as H406, A549 cells (with cell diameters of approximately $15 \mu \mathrm{m}$ ) have been widely used as research models for lung epithelial structure and the occurrence, development, and treatment of lung 
cancer [18-20]. In the present study, we conducted a preliminary clinical trial based on this finding and detected CTCs using indirect immunofluorescence in blood samples collected from an established subcutaneous lung cancer animal model using nude mice, rather than artificially mixing the cancer cells with blood. Contrary to the prediction that the cells of epithelial origin detected by the EpCAM antibody in the blood collected prior to inoculating cancer cells into nude mice would not be detected in this study, cell staining by indirect immunofluorescence showed positive results in 4 mice. This could have been due to many factors. It is possible that cells of epithelial origin contaminated orbital blood collection as a result of damage to the tissues surrounding the eyes.

Although the growth of tumor masses showed individual differences after the subcutaneous inoculation of H460 cancer cells, mass formation was successfully achieved in all nude mice. In addition, the number of cells stained by indirect immunofluorescence significantly increased in the blood collected before mass resection in 5 mice, except for mouse no. 2. However, there was no linear correlation between the size of the mass and the number of detected CTCs. This seems irrelevant to the characteristics of cancer cells because the same cell line was used; rather, it seems to be an issue of the sensitivity of the detection method, as well as individual differences in the number of CTCs.

A decrease in CTCs 2 weeks after mass resection was observed in all mice, except for mice no. 1 and 6. Recurrence of the mass was not observed in any of the experimental mice; however, mouse no. 1 showed a significant increase in the number of CTCs. This was believed to be associated with cancer metastasis to other areas. Although a biopsy was performed, there were no clear findings of metastasis to the lungs or other organs.

The CTC detection method using the commercial polycarbonate 12-well Transwell membrane (Corning Inc.) to isolate cells has the advantages of low cost and convenience for use in experiments, unlike other membrane filtering systems that require the assembly of detection equipment. In addition, the detection of CTCs in blood in an animal model of large cell lung cancer, rather than the detection of tumor cells in human blood mixed with cancer cells as in previous studies, is an experiment closer to the in vivo environment. Nonetheless, many stained cells were detected in the blood before the subcutaneous inoculation of cancer cells. In other words, the false-positive rate was high, and a disadvantage of this method is that the accuracy may be compromised by counting the number of stained cells vi- sually. Therefore, to reduce the false-positive rate, a method for reducing contamination of other cells during blood collection should be devised. Furthermore, it would be desirable to use an objective counting method using flow cytometry, such as fluorescence-activated cell sorting.

\section{Conflict of interest}

No potential conflict of interest relevant to this article was reported.

\section{Funding}

This work (research) was supported by the Chungnam National University Hospital Research Fund, 2009.

\section{ORCID}

Yooyoung Chong: https://orcid.org/0000-0002-1935-2140 Yong Chae Jung: https://orcid.org/0000-0001-7605-2630 Euidoo Hwang: https://orcid.org/0000-0003-3545-5593 Hyun Jin Cho: https://orcid.org/0000-0001-5833-5530 Min-Woong Kang: https://orcid.org/0000-0002-8492-0351 Myung Hoon Na: https://orcid.org/0000-0002-7458-1798

\section{References}

1. Travis WD, Travis LB, Devesa SS. Lung cancer. Cancer 1995;75(1 Suppl):191-202.

2. Paget S. The distribution of secondary growth in cancer of the breast. Lancet 1989;133:571-3.

3. Cristofanilli M, Budd GT, Ellis MJ, et al. Circulating tumor cells, disease progression, and survival in metastatic breast cancer. $\mathrm{N}$ Engl J Med 2004;351:781-91.

4. Cristofanilli M, Hayes DF, Budd GT, et al. Circulating tumor cells: a novel prognostic factor for newly diagnosed metastatic breast cancer. J Clin Oncol 2005;23:1420-30.

5. Mandair D, Khan MS, Lopes A, et al. Prognostic threshold for circulating tumor cells in patients with pancreatic and midgut neuroendocrine tumors. J Clin Endocrinol Metab 2021;106:872-82.

6. Cristofanilli M, Broglio KR, Guarneri V, et al. Circulating tumor cells in metastatic breast cancer: biologic staging beyond tumor burden. Clin Breast Cancer 2007;7:471-9.

7. Ballinger TJ, Smith ML, Miller KD. Evaluating the clinical utility of circulating tumor cells in metastatic breast cancer-is not worse good enough? JAMA Oncol 2021;7:30-1.

8. Allan AL, Keeney M. Circulating tumor cell analysis: technical and statistical considerations for application to the clinic. J Oncol 2010; 2010:426218. 
9. Shen Z, Wu A, Chen X. Current detection technologies for circulating tumor cells. Chem Soc Rev 2017;46:2038-56.

10. Alix-Panabieres C, Pantel K. Technologies for detection of circulating tumor cells: facts and vision. Lab Chip 2014;14:57-62.

11. Shahneh FZ. Sensitive antibody-based CTCs detection from peripheral blood. Hum Antibodies 2013;22:51-4.

12. Vona G, Sabile A, Louha M, et al. Isolation by size of epithelial tumor cells: a new method for the immunomorphological and molecular characterization of circulating tumor cells. Am J Pathol 2000;156: 57-63.

13. Kahn HJ, Presta A, Yang LY, et al. Enumeration of circulating tumor cells in the blood of breast cancer patients after filtration enrichment: correlation with disease stage. Breast Cancer Res Treat 2004;86:23747.

14. Zheng S, Lin H, Liu JQ, et al. Membrane microfilter device for selective capture, electrolysis and genomic analysis of human circulating tumor cells. J Chromatogr A 2007;1162:154-61.

15. Olsson AS, Robinson P, Pritchett K, Sandoe P. Animal research ethics. In: Hau J, van Hoosier GL, editors. Handbook of laboratory ani- mal science. 2nd ed. Boca Raton (FL): CRC Press; 2003. p. 13-31.

16. Bayne K, deGreeve P. An overview of global legislation, regulations and policies on the use of animals for scientific research, testing, or education. In: Hau J, van Hoosier GL, editors. Handbook of laboratory animal science. 2nd ed. Boca Raton (FL): CRC Press; 2003. p. $31-50$.

17. Festing MF. The design of animal experiments. In: Hubrecht R, Kirkwood J, editors. The UFAW handbook on the care and management of laboratory animals. 8th ed. Chichester: Wiley-Blackwell; 2010. p. 23-37.

18. Ali W, Moghaddam FJ, Raza MU, et al. Electromechanical transducer for rapid detection, discrimination and quantification of lung cancer cells. Nanotechnology 2016;27:195101.

19. Jiang RD, Shen H, Piao YJ. The morphometrical analysis on the ultrastructure of A549 cells. Rom J Morphol Embryol 2010;51:663-7.

20. Shashni B, Ariyasu S, Takeda R, et al. Size-based differentiation of cancer and normal cells by a particle size analyzer assisted by a cell-recognition PC software. Biol Pharm Bull 2018;41:487-503. 